\title{
Brazilian and Romanian decision-makers: is their decision behaviour different? evidence from an empirical study
}

\author{
Ana Maria Roux Valentini Coelho Cesar ${ }^{1, *}$, Gilberto Perez ${ }^{1}$, Larissa Batrancea ${ }^{2}$, \\ Anca Nichita ${ }^{3}$ and Ioan Batrancea ${ }^{4}$ \\ ${ }^{1}$ Applied Social Sciences Center, Mackenzie Presbyterian University, 896 Rua da Consolação, São Paulo, SP, Brazil \\ ${ }^{2}$ Department of Business, Faculty of Business, Babeş-Bolyai University, 7 Horea Street, Cluj-Napoca 400174, Romania \\ ${ }^{3}$ Department of Business Administration and Marketing, Faculty of Economic Sciences, '1 Decembrie 1918' University of Alba Iulia, \\ 15-17 Unirii Street, Alba Iulia 510009, Romania \\ ${ }^{4}$ Department of Finance, Faculty of Economics and Business Administration, Babeş-Bolyai University, 58-60 Teodor Mihali Street, \\ Cluj-Napoca 400591, Romania
}

\begin{abstract}
There are two types of processes involved while making a decision: a controlled process, which is rational, with introspective access and an automatic one, which is called experiential or decision by expertise. Both processes depend on the use of information and are influenced by social affective factors. The present study aims to identify the differences between decision behaviour adopted by managers in Brazil and Romania, when making decisions related to budget level estimation. The study is quantitative and the data were collected via a ten-point scale questionnaire on Brazilian and Romanian samples comprised of MBA students. The data were analysed using structural equation modelling estimated by means of the PLS methodology. Our results show that information search and social-affective factors influence both rational decision and decision by expertise in Brazil and Romania, however, in distinct degrees. Distinctions could arise based on cultural differences between Brazilian and Romanian decision-makers.
\end{abstract}

Keywords: Decision-making, cognitive models, neuroaccounting, management accounting.

THERE are two types of processes involved when making a decision: the controlled process (rational, with introspective access) and the automatic one, also called experiential $^{1,2}$. The latter is based on quick and parallel information processing, with several neural circuits simultaneously involved. Moreover, it is influenced by feelings and emotions and generally the subject is unaware of this fact. Since both processes depend on the use of information, it is necessary to consider that there are many types of information search (e.g. in academic journals, books, reports, media, etc.). Taking into account these aspects, we infer that information search and social

*For correspondence. (e-mail: anamaria.cesar@mackenzie.br) affective factors influence rational and automatic decision-making.

However, decisions are related to risk. More specifically, there are two important aspects to be considered in the business environment. First, scenarios are uncertain information sources and optimistic or pessimistic forecasts are made. These forecasts are not facts at the moment of the decision, but are a better information source than the absence of information. Second, human decisions are more complex than the models proposed to simulate them. Decisions involve careful considerations concerning risks and benefits related to an outcome and require a variety of behaviours involving alternative choices, possibilities and probabilities, and analysis and deductions of possible future consequences. Hence a model proposed to analyse the decision-making process is a simplification of the reality, although it is based on theoretical aspects that guarantee assumptions adopted and model restrictions.

In the area of economics, decision-making processes have been discussed extensively ${ }^{3-6}$. Being normative or descriptive, decision-making processes present some affective (i.e. emotions) and cognitive aspects (i.e. values, beliefs), but they also encompass intuition, which is considered to be the error of the $\operatorname{model}^{7}$.

In the last decade, numerous interdisciplinary studies have been conducted and there are various studies bringing together economics, cognitive neuroscience and cognitive psychology tackling topics as the following: the influence of impulsiveness on rationality ${ }^{8}$; the relationship between intuition, rationality and the experience of the decision-maker' the influence of the decision-maker's age on the decision-making process ${ }^{10}$; the regulation between pleasure of winning (or buying) and the pain of losing (or paying) ${ }^{11}$; the justice or injustice of the decision appraisal ${ }^{12}$; the influence of personality dimensions on decisions ${ }^{13}$; risk perception and threat detection in decision-making process ${ }^{14}$; the influence of the evaluation of affection and the state of 
mind on financial decisions ${ }^{15}$; the response latency in rational and non-rational decisions ${ }^{16}$; free will during decision-making and its link to neural systems ${ }^{17}$; differences in decision-making processes related to gender, namely mixed groups are more risk-taking than all-men groups ${ }^{18}$; the use of reinforcement learning to improve expertise in economic decision-making processes that lead to detrimental decisions ${ }^{19}$; the focus on overconfidence (a bias) regarding financial or economic decisions ${ }^{20}$ and vicarious learning from the experience of others ${ }^{21}$.

The novelty of the present study is the intercultural dimension that addresses decision-making behaviour and the application of a model integrating notions from economics and neuroscience, namely neuroeconomics.

\section{Problem qualification}

Within organizations, the effort of understanding the decision process is related to the strategic character of decisions in business environments. Rational decision-making requires time, conscious effort and adequate criteria to evaluate alternatives. However, business environment requires quick decisions, referred to as non-rational or automatic. These are based on the decision-maker's perceptions and experiences acquired in time and on the risks related to making decisions. Hence, the present study is grounded on the experience-based approach ${ }^{22}$, which proposes to examine how a decision is actually made, instead of how it must be made, as in the classic normative economic models of decision analysis.

Another assumption in the present study is that the process of managerial decision-making may vary from Brazil to other countries due to behavioural and cultural differences. Most studies on decision-making are conducted with samples drawn from the population of just one country. However, as proposed by Minkov and Hofstede $^{23}$, there are at least four dimensions in which country cultures could differ: power distance, individualism/collectivism, masculinity/femininity and uncertainty avoidance.

Based on the model of dual decision-making used for analysing decision processes and considering that differences in managerial decision-making could arise from the nationality of the decision-maker, the research question proposed in this study is the following: are there differences between the decision behaviour adopted by managers in Brazil and Romania? Therefore, the study aims to identify the differences between the decision behaviour displayed by managers in Brazil and Romania when deciding on budget level estimation.

The topic of the present study was chosen because estimating budget levels represents a common decisional situation within organizations. Even if budget estimation is not a participative process, employees are requested to pay attention to the budget levels during their daily activities in order for the organization to be able to abide by its proposed strategic planning. On the contrary, at a personal level, people make decisions about their financial budgets and make choices considering the risks and consequences of their decisions.

\section{Theoretical considerations}

Most of the earliest economic decision-making studies were conducted using experiments and were criticized because they lacked 'actual stimuli'. Nowadays studies regarding economic decisions focus on the phenomenon that needs to be elicited for providing meaningful insight. Most of these studies use experimental design and economic decision-making games. What differentiates studies in economics from the ones in psychology is that the former use monetary incentives ${ }^{24}$.

According to Borawska ${ }^{25}$ economic experiments concerning decision-making focus primarily on individual decision-making (especially under risk and uncertainty), inter-temporal choice and social decision-making; such studies examine the (ir)rationality of decision-makers. The literature tackles especially the evaluation and choice phases of the decision process using experimental design and economic games.

Revising the literature, we identified the following gap: there is a lack of intercultural studies comparing decision behaviour in different countries or comparing the behaviour of the decision-maker regarding day-to-day decisions. The theoretical approach considered in this study encompasses two decision-making models: first, a linear model based on cognitive psychology ${ }^{7}$; second, a bi-dimensional model, based on the dual decision-making theory, which brings insights from cognitive neuroscience studies $^{26}$.

\section{Linear decision-making model}

Pennings et $\mathrm{al}^{7}$ present a linear cognitive model for the decision-making process (Figure 1), though they emphasize that the decision process is complex and interactive, linearity being a simplification of the process that generates the decision (step 6 in Figure 1).

There are two important phases of the proposed decision model. The first phase called stimuli-relay (SR) involves the transformation of stimuli into perceptions, thus producing the multi-dimensional perceptual space (MDPS). The second phase called dynamic cognitive processing (DCP) represents the transformation of decision-maker's perceptions into behavioural possibilities. It consists of two complementary steps that interact: (a) computational step (CS), in which stored perceptions are analysed, importance or values are attributed to them and possible answers are produced. Memory has an important 


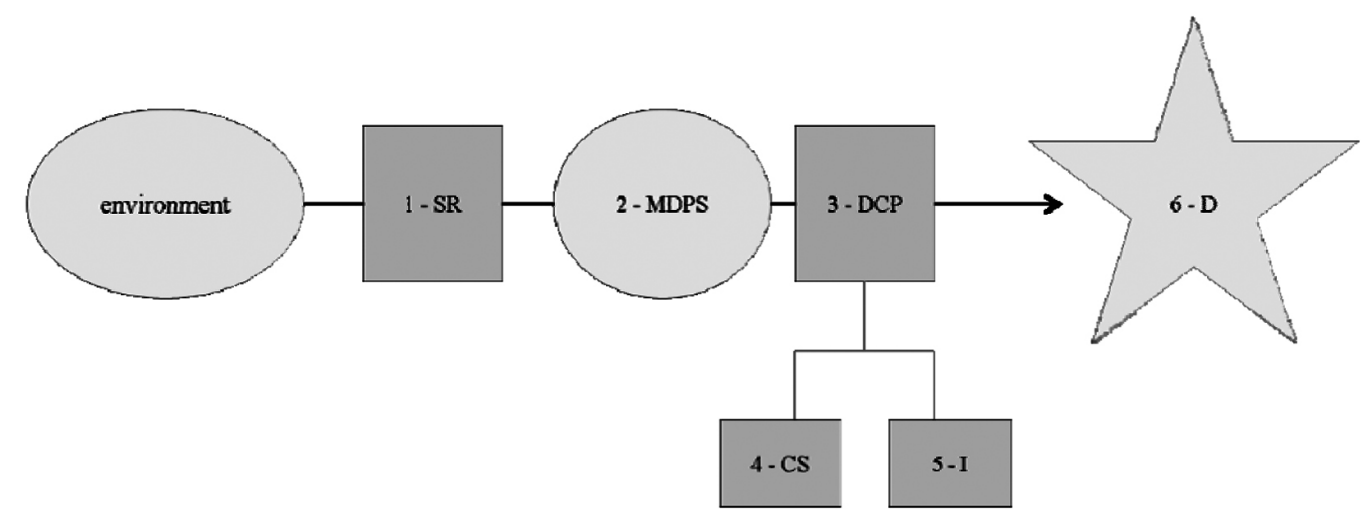

Figure 1. Linear decision-making model. Adapted from Pennings et al. ${ }^{7}$. Note: 1 - SR, Stimuli-relay; 2 - MDPS, Multidimensional perceptual space; 3 - DCP, Dynamic cognitive processing; 4 - CS, Computation step; 5 - I, Intuition; 6 - D, Decision.

role in this phase because it is the repository of previous learning; it allows conscious judgement of relevance of the information according to the decision-maker's goals; (b) intuition (I) in making alternative choices, without a formal analysis of data available for decision-making. This concept is related to implicit memory, algorithms of decision memorized for a given situation.

According to the model presented in Figure 1, a person acquires information from the environment (step 1) and filters it using selective attention mechanisms, producing relevant stimuli spaces (step 2). Since there is a great flow of available stimuli for the subject, the environment is considered a high-dimensionality space. Once this space is reduced, a set of relevant interpreted stimuli is generated, which represents the input for the algorithm used by decision-makers to make a choice, thus closing the SR phase. This stimuli interpretation depends on the contents of memory stored. In the SR stage, the social interaction effect influencing the information filter mechanism is highlighted.

The next stage is the information processing of MDPS, when alternatives that fulfil goals are chosen. This phase represents an input for the next phase called dynamic cognitive processing (DCP), when the decision-maker chooses the response to the problem in question ${ }^{7}$. As mentioned before, the DCP phase is divided into two interacting complementary steps, namely the computational step and the intuition step.

\section{Bi-dimensional decision-making model}

The idea of a bi-dimensional model for information processing was proposed by various researchers. Camerer et $a l .{ }^{26}$ presented one of these bi-dimensional models using neuroscience discoveries on neural functioning during information processing. Both dimensions proposed in their model refer to information processing approaches (i.e. controlled or automatic processes) and type of the accessed system (i.e. cognitive or affective). These two dimensions are intertwined to produce a four-quadrant model (Figure 2).

The control-automatism dimension mechanisms (superior and inferior quadrants in Figure 2, with the horizontal axis as reference) refer to the method by which information is processed in the brain. One method involves a controlled process, indicating that problem resolutions and decision-making imply conscious and active efforts (Figure 2, quadrants I and II). Another method involves an automatic process, indicating that quick resolutions and decisions are not made consciously, but are based on previous learning (Figure 2, quadrants III and IV). The cognition-affection dimension mechanisms (left and right sections in Figure 2, with the vertical axis as reference) show which systems are operated during information processing, namely the cognitive (reasoning) or affective systems (e.g. emotions, feelings, action-drivers).

Although quadrants I and II in Figure 2 include controlled processes of decision-making, in quadrant I the decision is controlled and related to cognitive systems, while in quadrant II the decision is controlled and related to affective systems. The classic models of decisionmaking are located in quadrant I. The automatic processes of decision-making are located in quadrants III and IV.

In the controlled process, information processing is serial, linear and follows logical steps; also, the decisionmaker is conscious about the effort applied to reach the decision (quadrants I and II, Figure 2). Simon ${ }^{4}$ pointed out that this process is not present in all decisions because human beings have limited computational capacity.

In the automatic process, information processing is parallel (involving several circuits), simultaneous, with connections between different routes in the brain, but also unconscious for the decision-maker. Parallelism produces redundancies, which facilitate the response speed and execution of multiple simultaneous tasks, increasing the 


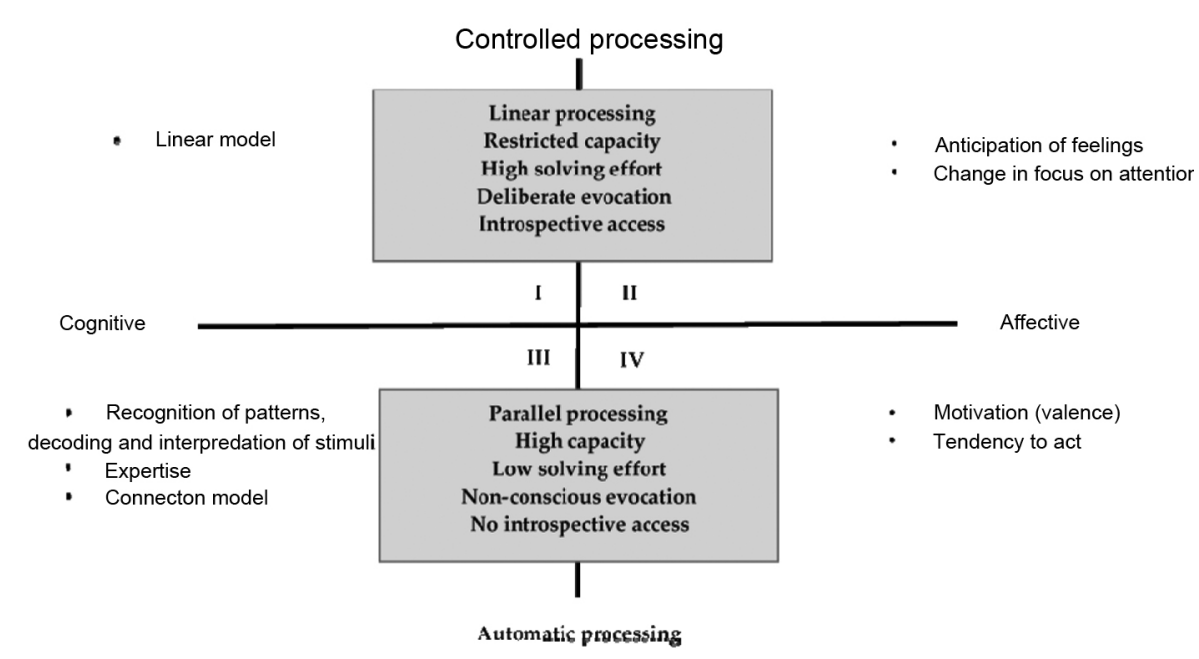

Figure 2. Bi-dimensional decision model. Adapted from Camerer et al. ${ }^{26}$.

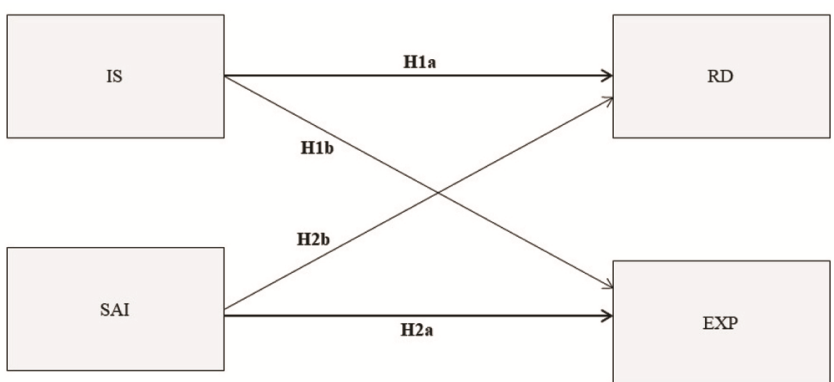

Figure 3. Proposed structural model. IS, Information search; SAI, Social affective influence; RD, Rational decision; EXP, Decision by expertise.

computational capacity of the brain. This system is operated when decisions are habitual and when quick decisions are demanded.

Affective and cognitive systems are interconnected and it is necessary to highlight that affections are not synonyms for emotions or feelings ${ }^{26}$. Emotion is an essential aspect of survival and is related to adaptive behavioural reactions ${ }^{27}$. Feelings are mental states related to the way a person 'feels" ${ }^{28}$. Affections include emotions, feelings and impulses (i.e. drive states) for action ${ }^{26}$. The affective dimension is important for the motivation of the decision, because positive or negative affections are related to the decision object, and they are responsible for questions regarding 'I will/I will not' 26 .

The cognitive dimension is responsible for reasoning and it is related to 'true/false' aspects. The cognitive system by itself does not direct behaviour, it needs to operate through the affective system. Expertise is a special type of automatic decision which is controlled by the cognitive system. Based on previous experience, the decisionmaker immediately identifies a standard (i.e. a situation already cataloged in his/her memory mechanism) in a specific problem and seeks an alternative resolution that has been already learned and memorized. As a problem arises frequently, the resolution tends to concentrate in specialized areas of the task processing, so that the problem is solved using an automatic process and with less effort. Since controlled processing entails significant effort, the brain constantly seeks to automate processes in order to increase its computational capacity. Expertise is part of what is called intuition in the model of Pennings et $a .^{7}$.

Affective and social aspects can influence both controlled and automatic decisions. In the automatic process, the influence is not conscious. In the controlled process, the influence is conscious and such aspects are present when the decision-maker analyses decision consequences for himself/herself or the group, or when the decisionmaker is under the group's influence, choosing the alternative that the group prefers and not his/her particular option.

In order to make decisions, it is necessary to have information. There are different types of information sources for the decision-maker, either formal (e.g. organizational reports, Government reports) or informal (e.g. social media, non-academic journals, non-academic reviews). The confidence that the decision-maker has in the information sources ultimately influences his/her decision.

Figure 3 shows the structural model tested in the present study, which compares decision-making in the Brazilian and Romanian samples.

Our study focused on decisions related to the forecasting level. Considering the theoretical framework of decision-making and the possibility of estimating the potential profit of a business unit, we have formulated the following hypotheses: In the task of estimating budgetary levels for both Brazilian and Romanian decision-makers: H1a: Information search (IS) impacts rational decision (RD; controlled); H1b: IS impacts decision by expertise (EXP; automatic); H2a: Social affective influence (SAI) 
impacts EXP (automatic); H2b: SAI impacts RD (controlled).

\section{Budget as a management control system}

The focus of the decision analysed in this study is the estimation of budges levels, one of the management control systems (MCS) developed as decision-supporting systems. While strategy formulation focuses on deciding new strategies (generally resulting from environmental or scenario analysis), MCS aims to guarantee that defined strategies are implemented ${ }^{29-31}$. MCS promotes target alignment within the organization, although it is known that such alignment is not always possible, since personal interests of the subjects, which outline these targets, often overlap with those of the organization ${ }^{31,32}$.

The budget, which pertains to MCS, presents the following characteristics: estimates the potential profit of a business unit; is expressed in monetary terms; is predicted for determined periods; is a management commitment, since, besides targets, it predicts measures that could be taken so that the accomplished results are compatible with the forecasted ones; and is developed based on information collected by the controlling area ${ }^{30}$. Besides being a forecasting tool, the budget is also a controlling tool that involves two levels of decision: the forecasting level, in which targets are established, and the approval level, in which target coherence is analysed.

\section{Method}

\section{Sampling procedure}

Our subject pool is characterized as being nonprobabilistic and convenient. Data from two samples were collected during the period 2015-2017 for the present study. Using the $G^{*}$ Power 3 software ${ }^{33}$, we estimated the minimum sample of 61 cases for a statistical power of 0.75 with a significance level of 0.05 and the size of the mean effect $(\mathrm{f} 2)=0.15$, which is considered a medium effect according to previous researchers.

The Brazilian sample included 64 subjects and the Romanian sample included 92 subjects, both above the calculated minimum value. In case of the Romanian sample, subjects were undergraduate, graduate and $\mathrm{Ph} \mathrm{D}$ students, some of them working part-time or full time. In the case of Brazilian sample, participants were MBA students working for companies from different economic sectors at the time of the survey. The subject pool consisted of comparable subsamples of male and female participants. Notwithstanding this, gender is not a control variable in the present study.

\section{Measurement model}

As shown in Figure 3, there are four constructs (latent variables) and all of them have between 5 and 7 indica- tors. The latent variables of the model are: IS, SAI, RD, EXP. Table 1 shows the latent variables and their indicators.

\section{Data collection and analyses}

Primary data were collected using a structured questionnaire developed for this study. The questionnaire was distributed during lectures. It contained affirmative statements expressing decision-making behaviour. Respondents had to indicate the frequency of their daily behaviour. We used a 10-point frequency scale (ranging from 1 to 10), each point representing $10 \%$. All constructs had reflective measurement models. The distribution of the variables resembled a normal curve (using graphical analysis, standardized skewness and kurtosis reached values between 0.8 and 4.2 , with positive skewness). Missing data were excluded from the analysis using list-wise deletion. There were no outliers in the distribution and all answers were within the range of values proposed in the questionnaire.

\section{Variable measurement}

The hypotheses were tested using descriptive and multivariate analysis. In order to test the proposed decisionmaking model, partial least squares structural equation modeling (PLS-SEM) was applied. This method allows incorporating into the analysis unobservable variables measured indirectly by indicator models ${ }^{34}$. The method also allows for the simultaneous estimation of multiple and inter-related dependence relationships.

\section{Results}

In this section, the results obtained from the Brazilian and Romanian samples are explained and compared.

\section{Structural model for the Brazilian sample}

Figure 4 presents the path model obtained based on Brazilian data. Three indicators were excluded because of their low factor loading in the model (below 0.5): v17 and v25 (EXP variable) and v24 (SAI variable). Therefore, the model was estimated with 25 indicators of the latent variables.

The model containing 25 indicators was statistically significant (Cronbach alpha $=0.5$; bootstrapping procedure with 63 degrees of freedom). The value of the $t$ test for the relationship IS-RD was 0.84, IS-EXP was 2.042, SAI-RD was 0.6 and SAI-EXP was 8.73. The relationships between SAI and RD, and also between IS and EXP were not significant. 
Table 1. Indicators and latent variables

\section{Indicators}

In uncertain scenarios, I seek a greater amount of information to make decisions.

In confusing scenarios, I seek a greater amount of information to make decisions.

When I make decisions, I seek information within the realms of the analysed topic.

I try to have feedback on previous decisions, considering these are information for new decisions.

Before making decisions, I seek general information about the situation.

When I make decisions, I seek systematic information in management reports or other documents.

To make decisions, I seek information that is external to the organization.

Indicator

number

Latent variables

v3

v7

v11

$\mathrm{v} 15$

v19

$\mathrm{v} 23$

v27

When deciding, I am afraid of making mistakes.

When I make decisions, I think about the impact of the decisions on my professional life.

When I make decisions, I consider my group's suggestions and influences.

When I make decisions, I am afraid of the risks involved with the decision.

When I make decisions, I think of the impact of my decisions on my personal life.

I make decisions based on my emotions.

Before making decisions, I think about possible errors in decision-making.

When I make decisions, I analyse the future scenario.

When I make decisions, I analyse the external economic scenario of the company.

When I make decisions, I analyse the external social scenario of the company.

When I make decisions, I analyse in detail all the alternatives.

I make decisions about assigning weight to alternatives according to their importance.

After making decisions, I analyse the results of my decisions and adjust direction if necessary.

When I make decisions, I analyse the value added of each alternative and choose one that has more aggregated value.

I make decisions based on internal or external recent factors of the company.

Social affective influence (SAI)

$\mathrm{v} 12$

$\mathrm{v} 16$

$\mathrm{v} 20$

$\mathrm{v} 24$

v28

In similar situations, I always make the same decision.

I make decisions based on my feelings.

I estimate the budgetary level considering a percentage of the previous year goals.

I make decisions with little mental effort.

I analyse the pattern of the situation; if it is similar to a previous situation, I use the same decision I have made in the past.

When I make decisions, I choose the most efficient strategy based on my experience.
Rational decision (RD)

Information search (IS)

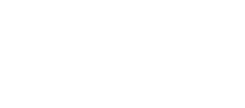

Decision by expertise (EXP)

Note: The number of variables indicates their order in the questionnaire.

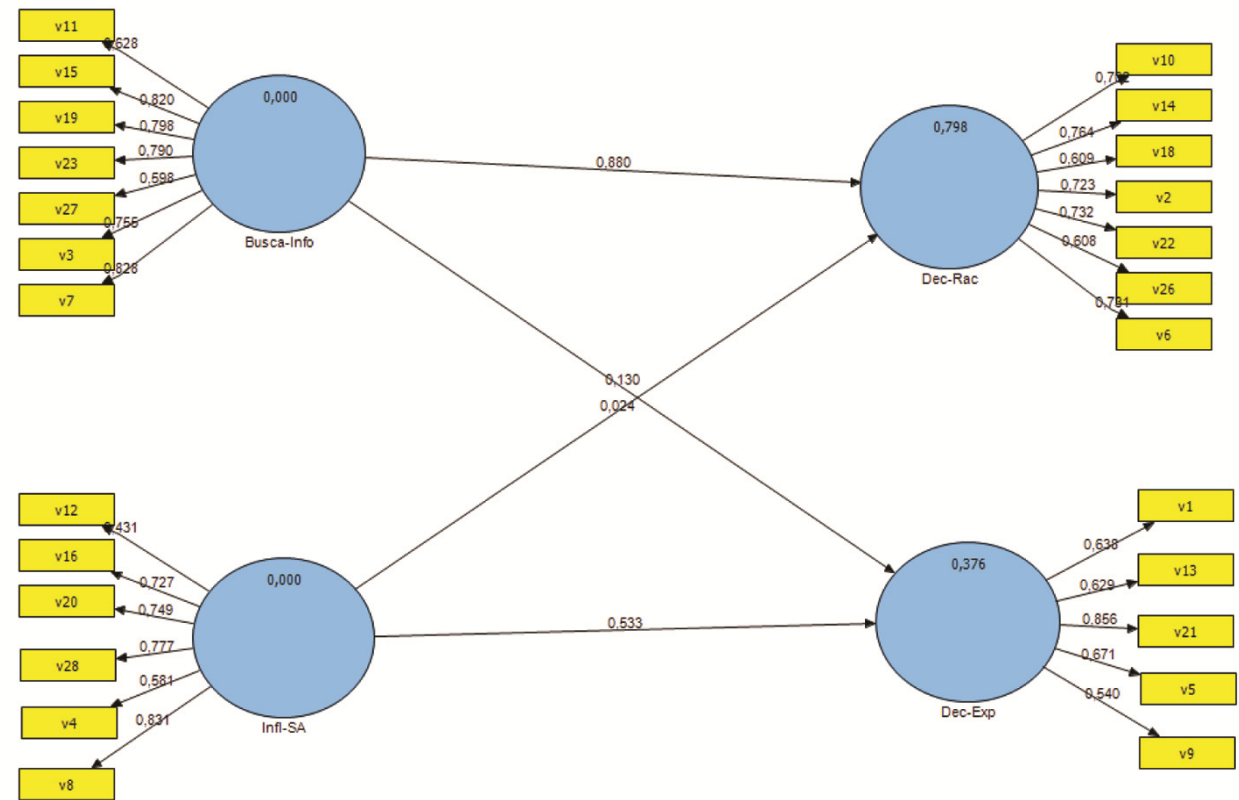

Figure 4. The structural model for the Brazilian sample. Busca-Info, Information search; Infl SA, Social affective influence; Dec-Rac, Rational decision and Dec-Exp, Decision by expertise. 
RESEARCH ARTICLES

Table 2. Parameters of the Brazilian model

\begin{tabular}{lcccc}
\hline $\begin{array}{l}\text { Latent } \\
\text { variables }\end{array}$ & $\begin{array}{c}\text { Convergent } \\
\text { validity (AVE) }\end{array}$ & Composite reliability & Cronbach's alpha & $R^{2}$ \\
\hline IS & 0.56293 & 0.89894 & 0.86673 & Independent variable \\
SAI & 0.48452 & 0.84435 & 0.77755 & Independent variable \\
RD & 0.48691 & 0.86839 & 0.82503 & 0.79815 \\
EXP & 0.45557 & 0.80333 & 0.69256 & 0.37567 \\
\hline
\end{tabular}

Table 3. Correlation between latent variables and discriminant validity (diagonal of the matrix) - Brazilian model

\begin{tabular}{lclll}
\hline $\begin{array}{l}\text { Latent } \\
\text { variables }\end{array}$ & IS & SAI & RD & EXP \\
\hline IS & 0.7502 & & & \\
SAI & 0.53876 & 0.6960 & & \\
RD & 0.89316 & 0.49847 & 0.6977 & \\
EXP & 0.41696 & 0.6031 & 0.42247 & 0.6750 \\
\hline
\end{tabular}

The proposed model is reflective. Hence we analysed its internal validity and reliability ${ }^{34}$, namely composite reliability, in order to analyse the consistency of the internal reliability; convergent validity, namely the average variance extracted (AVE) and discriminant validity. Tables 2 and 3 show these measures.

Convergent validity (AVE) is equivalent to the commonality of a construct. It indicates how the construct explains the variance of its indicators and can reach the maximum value of 1 . For the constructs in the model (latent variables), AVE was around 0.5, a value considered adequate. A value of 0.5 indicates that the outer loading of an indicator should be above 0.7 , since the squared number equals 0.5 (ref. 34).

Composite reliability and the Cronbach's alpha coefficient evaluate the consistency of internal reliability. All values for Cronbach's alpha were high (above 0.7), showing intercorrelations of the observed variables. Composite reliability varies from 0 to 1 ; hence values between 0.7 and 0.9 are generally regarded as satisfactory. In our case, values were above 0.8 , indicating higher levels of reliability.

Discriminant validity is the square root of AVE (i.e. Fornell-Larcker criterium). It compares the square root of AVE values with the correlations of the latent variables. The resulting measure should be greater than its higher correlation with any other construct. Table 3 presents the results. The exceptions were registered for the discriminant validity between IS and RD, namely the IS square root was 0.75 and the correlation between IS and RD was 0.89. However, the Fornell-Larcker criterium represents a conservative approach in assessing discriminant validity. Construct RD was kept in the model. According to Hair et $a .^{34}$, removing indicators may improve reliability or discriminant validity, but at the same time it may decrease the content validity of the measurement.
After reliability and validity criteria were established, we examined the coefficients of determination $\left(R^{2}\right.$ values), as well as the level and significance of path coefficients (Figure 4). According to the results, 79.8\% of RD and $37.6 \%$ of EXP were explained by IS and SAI. IS registered a high and significant loading on RD (i.e. 0.88). On the contrary, IS registered a low and non-significant loading on EXP (i.e. 0.13). Based on this result, in the case of Brazilian decision-makers, we cannot reject hypothesis H1a, but can reject $\mathrm{H} 1 \mathrm{~b}$.

SAI registered a low and non-significant loading on RD (i.e. 0.02) and a high and significant loading on EXP (i.e. 0.53). According to this result, for Brazilian decision-makers, we cannot reject hypothesis $\mathrm{H} 2 \mathrm{a}$, but can reject $\mathrm{H} 2 \mathrm{~b}$.

\section{Structural model for the Romanian sample}

Figure 5 presents the path model obtained on the Romanian data. One indicator was excluded because of its low factor loading in the model (below 0.5), namely v25 (EXP variable). In the end, the model was estimated with 27 indicators of the latent variables.

The model containing 27 indicators was statistically significant (Cronbach's alpha $=0.05$; bootstrapping procedure with 91 degrees of freedom). The value of the $t$ test for the relationship SI-RD was 28.60, for IS-EXP it was 1.17 , for SAI-RD it was 3.30, and for SAI-EXP it was 17.64. The relationships between SAI and RD, and also between IS and EXP were not significant.

The proposed model is reflective. Hence, we analysed its internal validity and reliability. Composite reliability, convergent validity and discriminant validity were also analysed. Tables 4 and 5 show these measures.

For the constructs (i.e. latent variables) included in the model, the convergent validity (AVE) registered a low value (from 0.33 to 0.44 ), indicating that the outer loadings should be around 0.6 , since that number squared equals 0.36 (ref. 34). All the values for Cronbach's alpha coefficients were adequate (above 0.62), indicating the inter-correlations of the observed variables. The composite reliability was above 0.75 , a level that can be regarded as satisfactory, thus indicating acceptable levels of reliability ${ }^{34}$.

The discriminant validity was evaluated by the square root of AVE (i.e. Fornell-Larcker criterium). Table 5 


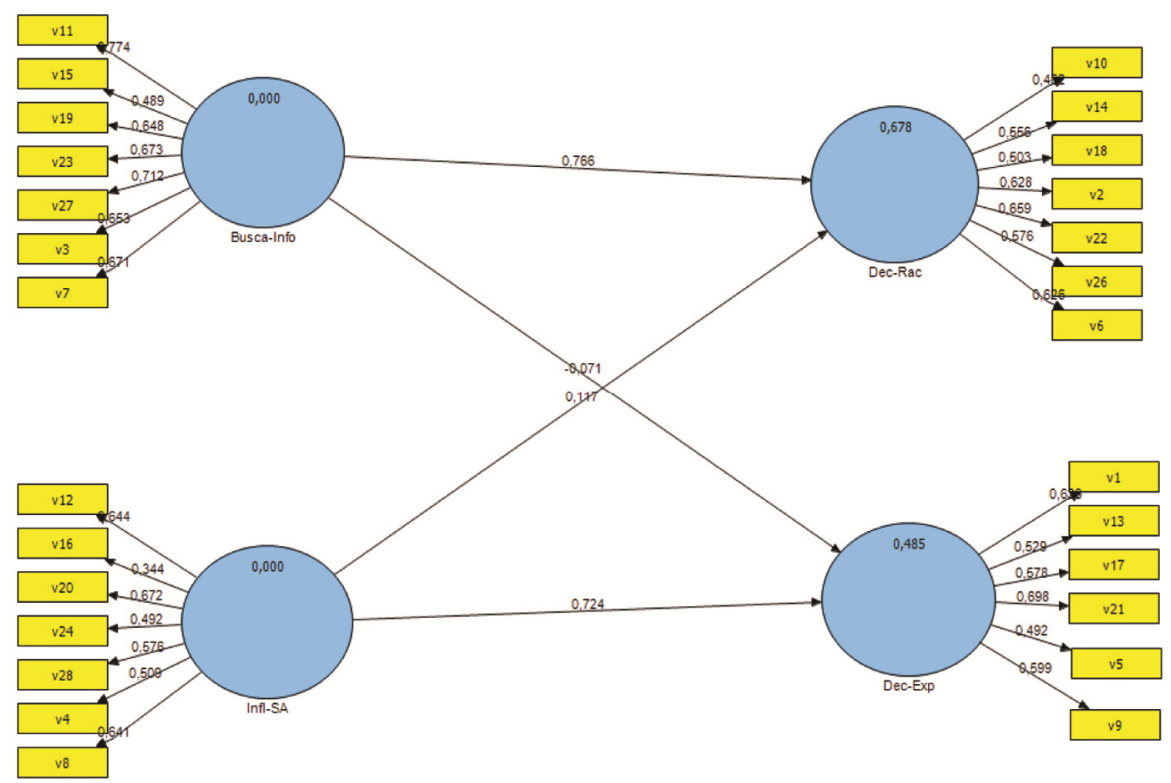

Figure 5. PLS-SEM results for the Romanian sample. Busca-Info, Information search; Infl SA, Social affective influence; Dec-Rac, Rational decision and Dec-Exp, Decision by expertise.

Table 4. Parameters of the Romanian model

\begin{tabular}{lcccc}
\hline Latent variables & $\begin{array}{c}\text { Convergent validity } \\
\text { (AVE) }\end{array}$ & Composite reliability & Cronbach's alpha & $R^{2}$ \\
\hline IS & 0.44199 & 0.845282 & 0.785634 & Independent variable \\
SAI & 0.318503 & 0.759256 & 0.635922 & Independent variable \\
RD & 0.48691 & 0.86839 & 0.82503 & 0.678 \\
EXP & 0.45557 & 0.80333 & 0.69256 & 0.485 \\
\hline
\end{tabular}

Table 5. Correlation between latent variables and discriminant validity (diagonal of the matrix)

\begin{tabular}{lllll}
\hline $\begin{array}{l}\text { Latent } \\
\text { variables }\end{array}$ & \multicolumn{1}{c}{ IS } & SAI & RD & EXP \\
\hline IS & 0.6648 & & & \\
SAI & 0.428576 & 0.5643 & & \\
RD & 0.816709 & 0.445663 & 0.4821 & \\
EXP & 0.239526 & 0.693694 & 0.339473 & 0.5902 \\
\hline
\end{tabular}

shows the results. Exceptions were registered for the discriminant validity between IS and RD (the square root for IS was 0.665 , and the correlation between IS and RD was 0.817 ), and between SAI and EXP (the square root for SAI was 0.564 , and the correlation between SAI and EXP was 0.694). However, as discussed before, the FornellLarcker criterium is a conservative approach for assessing the discriminant validity. All constructs were maintained in the model so as not to decrease the content validity of the measurement ${ }^{34}$.

We examined the coefficients of determination $\left(R^{2}\right.$ values), as well as the level and significance of path coefficients. The results indicate that $67.8 \%$ of RD and $48.5 \%$ of EXP were explained by IS and SAI. IS registered a high and significant loading (0.76) on RD, and a low and non-significant loading on EXP (-0.071). Based on this result, in the case of Romanian decision-makers, we cannot reject hypothesis $\mathrm{H} 1 \mathrm{a}$, but can reject $\mathrm{H} 1 \mathrm{~b}$.

SAI registered a low and non-significant loading on RD (i.e. 0.11), and a high and significant loading on EXP (i.e. 0.72). According to this result, for Romanian decision-makers, we cannot reject hypothesis $\mathrm{H} 2 \mathrm{a}$, but we can reject $\mathrm{H} 2 \mathrm{~b}$.

When comparing Brazilian and Romanian models, we found that H1a and H2a were confirmed for both models, but there were differences between the loadings of each indicator and their latent variables. Table 6 shows these differences.

As can be seen from Table 6, there are differences in the indicator loadings for the latent variables in both Brazilian and Romanian models. All loadings of the Brazilian sample were higher than loadings corresponding to the Romanian sample, except the loadings of v11 (IS variable), v12 (SAI variable) and v27 (IS variable).

The most common measure to evaluate the structural model is the coefficient of determination ( $R^{2}$ value), which estimates the predictive accuracy of the model. The coefficient captures the combined effects of the 
exogenous latent variables on the endogenous latent variables. It also explains the amount of variance in the endogenous constructs that are explained by all exogenous constructs linked to $\mathrm{it}^{34}$. Table 7 shows that rational decision is better explained than decision by expertise, in both Brazilian and Romanian models.

However, there are differences in the number of exogenous variables included in the two models: the model estimated on the Romanian sample considered two variables (v17 and v24) that were not included in the Brazilian model. Taking into account $R^{2}$ of the Romanian model (all variables included) and that of the Brazilian model, it is possible to calculate the effect size in order to see if omitted exogenous indicators had a substantial impact on latent variables (endogenous construct). The effect size was determined as follows: $\left(R^{2}\right.$ of Romanian model $-R^{2}$ of Brazilian model $) /\left(1-R^{2}\right.$ of Romanian model).

The effect value for RD was 0.37 , which is generally considered high $^{34}$, indicating that $\mathrm{v} 4$ (excluded from the

Table 6. Indicator loadings on the latent variables

\begin{tabular}{|c|c|c|}
\hline \multirow[b]{2}{*}{ Indicators } & \multicolumn{2}{|c|}{ Loadings } \\
\hline & Brazil & Romania \\
\hline \multicolumn{3}{|l|}{ IS } \\
\hline v3 & 0.756 & 0.653 \\
\hline v7 & 0.828 & 0.671 \\
\hline v11 & 0.628 & 0.774 \\
\hline v15 & 0.820 & 0.489 \\
\hline v19 & 0.798 & 0.648 \\
\hline v23 & 0.790 & 0.673 \\
\hline v27 & 0.598 & 0.712 \\
\hline \multicolumn{3}{|l|}{ SAI } \\
\hline v4 & 0.581 & 0.509 \\
\hline v8 & 0.831 & 0.641 \\
\hline v12 & 0.431 & 0.644 \\
\hline v16 & 0.727 & 0.344 \\
\hline v20 & 0.749 & 0.672 \\
\hline v24 & & 0.492 \\
\hline v28 & 0.777 & 0.576 \\
\hline \multicolumn{3}{|l|}{ RD } \\
\hline v2 & 0.723 & 0.628 \\
\hline v6 & 0.781 & 0.626 \\
\hline v10 & 0.782 & 0.452 \\
\hline v14 & 0.764 & 0.556 \\
\hline v18 & 0.609 & 0.503 \\
\hline v22 & 0.732 & 0.659 \\
\hline v26 & 0.608 & 0.576 \\
\hline \multicolumn{3}{|l|}{ EXP } \\
\hline v1 & 0.638 & 0.626 \\
\hline v5 & 0.671 & 0.492 \\
\hline v9 & 0.540 & 0.599 \\
\hline v13 & 0.629 & 0.529 \\
\hline v17 & & 0.578 \\
\hline v21 & 0.856 & 0.698 \\
\hline
\end{tabular}

Note: Empty cells highlight the indicators that did not fit the Brazilian model, just the Romanian model.
Brazilian model) could have an impact on RD. The effect value for EXP was 0.21 , which is generally considered as medium $^{34}$, indicating that v17 (excluded from the Brazilian model) had a relative impact on EXP.

Table 8 provides a summary of the conclusions regarding the hypotheses.

\section{Discussion}

We now highlight the main results of the study. First, an interesting result was that the coefficient of determination for RD was higher than that for EXP in both models (i.e. Brazilian and Romanian). EXP represents an automatic decision: it is not always conscious, is fast and used in most decisions made on a daily basis, with the help of cognitive and affective systems. This result highlights one of the limitations of this study. Since decisions were analysed by self-declarations through a survey, the actual behaviour of the subject could not be captured as it occurs in practical decisional situations because decisionmakers may not be aware of the mechanisms they employ to decide. Experimental studies have been conducted involving decision games in which subjects decided on investment levels based on a set of management accounting statements $^{35}$. As the aforementioned study used neuroscience instruments like EEG to capture the neural circuits involved in decisions, it could be stated that participants learned the rule to make estimates of target levels, a rule that was not explicitly presented to them during the game. However, at the end of the experiment, none of the subjects was aware of deciding according to the game rules. They claimed they had used rational mechanisms to make estimates. In addition, the EEG showed that the subjects' brains had captured a degree of incongruity regarding the information presented to them in order to be used as the basis for decision-making, but the subjects did not realize this consciously.

A second aspect to be highlighted is participants' statements according to which about $50 \%$ of the time when deciding on budget targets they did not follow the parameters indicated by the company. At least 16 management accounting system techniques could be identified

Table 7. Coefficients of determination for the Brazilian and Romanian models

\begin{tabular}{lcccc}
\hline & $\begin{array}{c}\text { Convergent } \\
\text { validity } \\
\text { (AVE) }\end{array}$ & $\begin{array}{c}\text { Composite } \\
\text { reliability }\end{array}$ & $\begin{array}{c}\text { Cronbach's } \\
\text { alpha }\end{array}$ & $R^{2}$ \\
\hline Brazilian model & & & & \\
$\quad$ RD & 0.48691 & 0.86839 & 0.82503 & 0.798 \\
EXP & 0.45557 & 0.80333 & 0.69256 & 0.375 \\
Romanian model & & & & \\
RD & 0.48691 & 0.86839 & 0.82503 & 0.678 \\
EXP & 0.45557 & 0.80333 & 0.69256 & 0.485 \\
\hline
\end{tabular}


Table 8. Results regarding hypotheses of the study

\begin{tabular}{lll}
\hline & \multicolumn{1}{c}{ Hypothesis } & \multicolumn{1}{c}{ Brazil } \\
\hline H1a & Information search impacts the rational decision (controlled). & Confirmed \\
H1b & Information search impacts decision by expertise (automatic). & Not confirmed \\
H2a & Social affective influence impacts decision by expertise (automatic). & Confirmed Not confirmed \\
H2b & Social affective influence impacts the rational decision (controlled). & Not confirmed Confirmed Not Confirmed \\
\hline
\end{tabular}

Table 9. Comparison between Brazil and Romania in Hofstede's dimensions

\begin{tabular}{lcc}
\hline Dimensions & Brazil & Romania \\
\hline Power distance & 69 & 90 \\
Individualism & 38 & 30 \\
Masculinity & 49 & 42 \\
Risk aversion & 76 & 90
\end{tabular}

Source: https://geert-hofstede.com (accessed on 27 January 2016) ${ }^{41}$.

and classified as costing, planning, control and performance measurement and decision-making. Firm performance was generated by the use of 'an appropriate match between contingent factors and strategic management accounting, ${ }^{36}$. Therefore, an important question arises: If people do not use parameters, why do firms develop financial information systems or MCS, which provide information for internal users? ${ }^{37}$.

The limited use of parameters as indicated by respondents may be explained by the fact that the parameters used by companies to guide decisions could be perceived as inappropriate or outdated compared to reality at the moment of the decision. Information systems include inputs (e.g. data and instructions) and outputs (e.g. reports and calculations), but also persons, proceedings and physical facilities operating in a determined environment $^{38,39}$. Parameters could be perceived as having been set by people who may not know the reality according to which the decision is taken, at least not as much as the one who actually decides. Therefore, one question arises frequently: What are the consequences of a 'bad estimation' if parameters were violated? Findings suggest that people must be motivated to use parameters in high-risk situations, but not in their daily activities.

Another aspect worth noticing is that fixed parameters in highly changeable environments could be strong inducers of decision biases. Disregarding some parameters is not a bad fact in itself. After all, in order to make decisions, one needs to solve the problem that generates decision alternatives. The functional attachment, one of the problems in generating new alternatives in a decision situation, represents an obstacle to creative solutions ${ }^{40}$.

An interesting finding of the survey is that SAI was not confirmed as being present when decisions were based on rationality. This result was not consistent with the observations made by Kahneman ${ }^{1}$, according to which attain- ing consistency in rationality was absolutely restrictive. As stated by Kahneman, 'rationality is logical coherence - be it reasonable or not'. Sometimes it can be 'unreasonable'. Nevertheless, one should consider that people are free to choose and use this freedom regardless of restrictions.

Within the management accounting field, as pointed out by Cadez and Guilding ${ }^{36}$, it is interesting to note that strategic practices are relatively new and they are not to be found in normative accounting texts before the 1980s. Therefore, studies in management accounting practices and classic economic decision were not conducted in the same period of time. Considering the timing, the present study may be considered an advancement in decisionmaking studies within the field of management accounting because it explores daily behavioural aspects of the decision-making process. All items in the questionnaire were related to management accounting practices, describing situations pertaining to the role of management and suggesting the use of heuristics and biases.

In order to compare the models estimated for the Brazilian and Romanian samples, we used Hofstede's dimensions (Table 9).

Romania registered a higher index of power distance than Brazil. This difference could explain, among others, the reason for which the loading of v12 is lower in the Romanian model than in the Brazilian model. Regarding the difference in the loadings of v16, it could be explained by the risk avoidance behaviours displayed in both samples. More specifically, Romanians were generally more risk-averse than Brazilians. Hence, Romanian decision-makers were probably more cautious in taking risks than their Brazilian counterparts and they needed more information (v11) than Brazilian decision-makers.

\section{Conclusion}

The main objective of this study was to identify the differences between the decision behaviour displayed by managers in Brazil and Romania when deciding on budget level estimation. The study shows that structural models (i.e. the relationship between latent variables) are similar in the case of the Brazilian and Romanian samples because our hypotheses were confirmed or rejected in a similar way for both models. However, measurement models (i.e. the relationships between latent variables and indicators) are different as discussed in the text. This 
result indicates that intercultural studies on decisionmaking are important for the development of decision support tools in the field of management accounting.

The limitations of the present study should also be discussed. First, although the proposed model is complex because it used indicators related to decisions and the theoretical framework, it may be regarded as incomplete because there are other decisional aspects that have not been considered. Industry, technology, geographical environment and cultural aspects are variables that could be examined in future studies designed to understand the decision-making process within accounting environments. Secondly, the use of budget in organizations where the respondents worked was not controlled in this study.

One must consider the statement of Kahneman ${ }^{1}$, according to which 'not being rational' is different from being irrational, when irrationality is viewed as impulsivity, emotionality and resistance to the 'reasonable argument'. It is important to emphasize that people use rationality, but only aspects related to the affective domain (including decision-making heuristics and motivational aspects) can overcome their limited ability to process information. This aspect suggests that similar experimental studies should be conducted using simulations of decisions in financial environments and neuroscience tools that capture aspects of real-time brain functioning. In other words, advancement in neuroaccounting area is required.

In terms of novelty, we highlight the consistency and rigour of the method used (i.e. structural equations model), as well as the implications and contributions of the study for the literature, business environment and academic community. The constructs studied reflect the behaviour of the decision-maker in day-to-day activities within organizations. We also emphasize the use of the perceived frequency scale regarding the decision-maker's behaviour. An important aspect to emphasize is that this study had a preliminary and rich qualitative stage as part of a larger project that has not been addressed here.

Finally, our study can contribute in practical terms to the discussion about the adaptation of management accounting tools in organizations that are based in different countries. Results show that what is valid for one country may not have the same weight for making decisions in a different country. A viable perspective regarding the continuity of the study would be to conduct the survey in countries from different parts of the globe.

1. Kahneman, D., Rápido e Devagar: Duas Formas de Pensar, Objetiva, Rio de Janeiro, Brazil, 2012.

2. Hogarth, R. M., Portell, M., Cuxart, A. and Kolev, G., Emotion and reason in everyday risk perception. J. Behav. Decis. Making, 2011, 24, 202-222; doi:10.1002/bdm.689.

3. von Neumann, J. and Morgenstern, O., Theory of Games and Economic Behavior, Princeton University Press, Princeton, NJ, USA, 1944
4. Simon, H. A., A behavioural model of rational choice. Q. J. Econ., 1955, 69(1), 99-118; doi:10.2307/1884852.

5. Kahneman, D. and Tversky, A., Prospect theory: an analysis of decision under risk. Econometrica, 1979, 47(2), 263-291; doi: $10.2307 / 1914185$.

6. Hogarth, R. M. and Karelaia, N., Simple models for multiattribute choice with many alternatives: when it does and does not pay to face trade-offs with binary attributes. Manage. Sci., 2005, 51(12), 1860-1872; doi:10.1287/mnsc.1050.0448.

7. Pennings, J. M. E., Garcia, P. and Hendrix, E., Towards a theory of revealed economic behaviour: the economic-neuroscience interface. J. Bioecon., 2005, 7(2), 113-137; doi:10.1007/s10818-0056417-z.

8. Franken, I. H., Van Strien, J. W., Nijs, J. and Muris, P., Impulsivity is associated with behavioural decision-making deficits. Psychiatr. Res., 2008, 158(2), 155-163; doi:10.1016/j.psychres.2007.06.002.

9. Hon-Snir, S., Kudryavtsev, A. and Cohen, G., Stock market investors: who is more rational, and who relies on intuition? Int. J. Econ. Financ., 2012, 4(5), 56-73; doi:10.5539/ijef.v4n5p56.

10. Brown, S. B. R. E. and Ridderinkhof, K. R., Aging and the neuroeconomics of decision making: a review. Cogn. Affect. Behav. Neurosci., 2009, 9(4), 365-379; doi:10.3758/CABN.9.4.365.

11. Raab, G., Elger, C. E., Neuner, M. and Weber, B., A neurological study of compulsive buying behaviour. J. Consum. Policy, 2011, 34, 401-413; doi:10.1007/s10603-011-9168-3.

12. Trzaskowski, J., Behavioural economics, neuroscience, and the unfair commercial practices directive. J. Consum. Policy, 2011, 24, 377-392; doi:10.1007/s10603-011-9169-2.

13. Weller, J. A. and Tikir, A., Predicting domain-Specific risk taking with the HEXACO personality structure. J. Behav. Decis. Making, 2011, 24, 180-201; doi:10.1002/bdm.677.

14. Gao, X., LoBue, V., Irving, J. and Harvey, T., The effect of spatial frequency information and visual similarity in threat detection. Cogn. Emotion, 2016, 31(5), 912-922; doi:10.1080/02699931. 2016.1180280.

15. Peterson, R. L., Affect and financial decision-making: how neuroscience can inform market participants. J. Behav. Financ., 2007, 8(2), 70-78; doi:10.1080/15427560701377448.

16. Rubinstein, A., Instinctive and cognitive reasoning: a study of response times. Econ. J., 2007, 117, 1243-1259; doi:10.1111/j. 1468-0297.2007.02081.x.

17. Wilson, R. M., Gaines, J. and Hill, R. P., Neuromarketing and consumer free Will. J. Consum. Affairs, 2008, 42(3), 389-410; doi:10.1111/j.1745-6606.2008.00114.x.

18. Lamiraud, K. and Vranceanu, R., Group gender composition and economic decision-making: evidence from the Kallystée business game. J. Econ. Behav. Organ., 2018, 145, 294-305.

19. Hügelschäfer, S. and Achtziger, A., Reinforcement, rationality, and intentions: how robust is automatic reinforcement learning in economic decision making? J. Behav. Decis. Making, 2017, 30(4), 913-932.

20. Raharja, B. S., Suhaeli, D. and Mranani, M., Did manager behave overconfidently? Financ. Stud., 2017, 21(3), 32-44.

21. Harrison, R., Mason, C. and Smith, D., Heuristics, learning and the business angel investment decision-making process. Entrepreneur. Reg. Dev., 2015, 27(9-10), 527-554.

22. Rakow, T. and Newell, B. R., Degrees of uncertainty: an overview and framework for future research on experience-based choice. J. Behav. Decis. Making, 2010, 23, 1-14; doi:10.1002/bdm.681.

23. Minkov, M. and Hofstede, G., The evolution of Hofstede's doctrine. Cross Cult. Manag., 2011, 18(1), 10-20; doi:10.1108/ 13527601111104269 .

24. Gupta, A., Kannan, K. and Sanyal, P., Economic experiments in information systems. MIS $Q$., 2018, 42(2), 595-606.

25. Borawska, A., Cognitive neuroscience tools in economic experiments investigating the decision making process. Folia Oecon. Stetin., 2017, 17(1), 159-169. 
26. Camerer, C. F., Loewenstein, G. and Prelec, D., Neuroeconomics: how neuroscience can inform economics. J. Econ. Lit., 2005 43(1), 9-64; doi:10.1257/0022051053737843.

27. Goleman, D., Emotional Intelligence, Bantam, New York, USA, 1995.

28. Viscott, D., The Language of Feelings, Pocket Books, New York, USA, 1982

29. Merchant, K. and Van der Stede, W., Management Control Systems: Performance Measurement, Evaluations and Incentives, Pearson, New York, USA, 2007, 2nd edn.

30. Anthony, R. N. and Govindarajan, V., Sistemas de Controle Gerencial, McGraw Hill, Brazil, 2008.

31. Horngren, C. T., Sundem, G. L. and Stratton, W. O., Introduction to Management Accounting, Pearson Education, NJ, USA, 2005.

32. Baron, J. N. and Kreps, D. M., Strategic Human Resources: Farmework for General Managers, Wiley \& Sons, New York, USA, 1999.

33. Faul, F., Erdfelder, E., Buchner, A. and Lang, A.-G., Statistical power analyses using $G^{*}$ Power 3.1: tests for correlation and regression analyses. Behav. Res. Meth., 2009, 41, 1149-1160.

34. Hair, J. F., Hult, G., Thomas, M., Ringle, C. M. and Sarstedt, M., A Primer on Partial Least Squares Structural Equation Modeling (PLS-SEM), Sage Publications, Los Angeles, CA, USA, 2014, 2nd edn.

35. Cesar Roux, V. C., A. M., Boggio, P. S. and Campanhã, C., Neuroeconomia: Uma Visão Geral Sobre o Tema. In Guia de Economia Comportamental e Experimental (eds Ávila, F. and
Bianchi, A. M.), Economia Comportamental.org: São Paulo, SP, Brazil, 2015, pp. 250-262.

36. Cadez, S. and Guilding, C., An exploratory investigation of an integrated contingency model of strategic management accounting. Account. Organ. Soc., 2008, 33(7-8), 836-863; doi:10.1016/ j.aos.2008.01.003.

37. Wilkinson, J. W., Accounting and Information Systems, John Wiley, New York, USA, 1991.

38. O’Brien, J. A. and Marakas, G. M., Administração de Sistemas de Informação: Uma Introdução, McGraw-Hill, São Paulo, SP, Brazil, 2008, 13th edn.

39. Turban, E., McLean, E. and Wetherbe, J., Tecnologia da Informação para Gestão, Bookman, Porto Alegre, Brazil, 2007, 3 rd edn.

40. Sternberg, R. J., Psicologia Cognitiva, Artmed, Porto Alegre, Brazil, 2008.

41. https://geert-hofstede.com (accessed on 27 January 2016).

ACKNOWLEDGEMENTS. The authors acknowledge the support from Conselho Nacional de Desenvolvimento Científico e Tecnológico Project number 477668/2012-7 and Mackenzie Presbyterian University, São Paulo, Brazil.

Received 12 June 2018; revised accepted 11 October 2018

doi: $10.18520 / \mathrm{cs} / \mathrm{v} 116 / \mathrm{i} 3 / 445-456$ 